\title{
ECOLOGICAL
} MODELLING

\section{Structural changes in an estuary, described by models and using exergy as orientor}

\author{
Sven Erik Jørgensen ${ }^{\mathrm{a}, *}$, Joao Marques $^{\mathrm{b}}$, Søren Nors Nielsen ${ }^{\mathrm{a}}$ \\ ${ }^{a}$ Institute A, Section for Environmental Chemistry, DFH, University Park 2, 2100 Copenhagen Ø, Denmark \\ ${ }^{\mathrm{b}}$ IMAR, Department of Zoology, Faculty of Science and Technology, Coimbra University, Coimbra, Portugal
}

\begin{abstract}
It is often of interest to determine which structure of an ecosystem among the possible ones will prevail under given environmental circumstances. The authors show that it is feasible using models and an exergy index. The hypothesis is that the structure giving the highest exergy will prevail. The exergy calculations are however still very uncertain, which implies that a clear difference in exergy must be required. The method has been tested successfully in this paper presenting the case study of Mondego Estuary, Portugal. The method seems to have a general applicability as it also has been used successfully to predict structural changes and to improve model calibrations (see for instance Jørgensen et al., submitted for publication and Jørgensen, 2002).
\end{abstract}

(C) 2002 Published by Elsevier Science B.V.

Keywords: Structural changes; Ecological modelling; Exergy; Mondego estuary; Zostera; Enteromorpha

\section{Introduction}

It is often of interest to determine among several possibilities which structure of an ecosystem will prevail under given environmental circumstances. It has previously been proposed (Jørgensen and Mejer, 1979 and Jørgensen, 1992) to use the thermodynamic variable, exergy as an orientor to describe adaptation and changes in the species composition. This approach has been applied now 13 times for validation of various models (most of these case studies can be found in Jørgensen, 1997; Jørgensen et al., 2000). It does however not

* Corresponding author. Fax: +45-35375744

E-mail addresses: sej@dfh.dk (S.E. Jørgensen),snn@dfh.dk (S.N. Nielsen). exclude that other orientors can be used to obtain the same results. The approach has also been applied to improve model calibration with the idea that the observations used for a calibration of course also reflect the adaptability and composition change of species according to the prevailing conditions (Jørgensen, 1998; Jørgensen and Bendoricchio, 2001 and Jørgensen et al., submitted for publication). This paper will present a third application possibility of the approach, namely to decide which of two possible structures of an ecosystem that will win under which conditions.

In the Mondego estuary, two very different types of communities have been observed (Marques et al., 1997):

(1) An Enteromorpha dominant community with the presence of Cyathura carinata, mollusca 
and crustacea. The algae community shows often a crash at early summer due to oxygen depletion. This community is found where the salinity is not too low and the nutrient concentration is high.

(2) A Zostera nolti dominant community with the presence of oligochaeta, polychaeta, mollusca and crustacea. Mollusca is more abundant in this ecosystem than in ecosystem (1), while crustacea are more abundant in community (1) than in community (2). This ecosystem is found where the nutrient concentration is lower.

We use two ecosystem models, compute and compare an exergy index for several conditions. The hypothesis is that the ecosystem structure having the highest exergy index among the possible ones will prevail, which is determined by models. If the hypothesis is correct, a comparison of models for the two types of ecosystems should show that the highest exergy under eutrophied and medium to high salinity conditions is found for ecosystem (1), while the highest exergy should be found for ecosystem (2) under low nutrients and low salinity conditions.

\section{The models}

The conceptual diagrams, using STELLA, for the two models are shown in Figs. 1 and 2. The equations are indicated in Appendix 1. The model for the Enteromorpha is almost completely in accordance with Martins and Marques (in press). A few parameters are slightly different probably because slightly different data have been applied for the calibration. The growth is described as a two steps process: uptake of nutrients and growth based upon the internal nutrient concentration. These processes are dependent on the temperature, the radiation, the nutrient concentration in the water phase, the salinity (there is an optimum salinity for growth of Enteromorpha) and the oxygen concentration (the growth rate decreases when the oxygen concentration is below about 5 $\mathrm{mg} / \mathrm{l})$. This model has been successfully calibrated and validated (Martins and Marques, in press). The growth is described as a function of internal concentrations of nutrients, temperature, light and salinity (Duarte, 1995).
In addition to the Enteromorpha model bivalves and crustacea are lumped as one state variable, crsmul, feeding on detritus. The model is calibrated to fit the observations presented by Marques et al. (1997) with an algae crash in June due to oxygen depletion.

Freshwater is discharged to the estuary from day 213 to 365 with a peak day 274. It is described as a dilution of the salt water to be compatible with the tide water where a sin function describes the fluctuations between 0 and $2 \mathrm{~m}$. Salinity, temperature and light are considered forcing functions of the model.

It was decided to limit the complexity to the following 7 state variables: entero (Enteromorpha); PS, soluble P; NS, soluble N; Pinentero, P in Enteromorpha; Nintero, $\mathrm{N}$ in Enteromorpha, crsmul, bivalves and crustacea; and Detritus, because the exergy calculations in Marques et al. (1997) show clearly that the main contributions to the exergy of the system is coming from these components.

The state variables entero, Detritus and crsmul were expressed as $\mathrm{g} / \mathrm{m}^{2}$, while PS, Pinentero, NS and Ninentero are expressed as $\mu \mathrm{mol} / \mathrm{m}^{2}$.

The Zostera nolti (eel grass) model is completely in accordance with the model presented in Bocci et al. (1997) with addition of two state variables namely crsmul for bivalves and crustacea and detritus. The model is using the same units and forcing functions as the Enteromorpha model, but the Zostera nolti model has one more state variable covering the roots. The other state variables are basically the same as in the Enteromorpha model. The model distinguishes between shoots and roots. It implies that nutrients can be taken up both from water and from the sediment through the roots. The growth of eel grass is therefore much less sensitive to the variations in the nutrient concentration of the water. Eel grass is furthermore less sensitive to the salinity and a crash does not occur, because sufficient oxygen is produced by eel grass to prevent oxygen depletion.

Exergy is found according to the equation Exergy $=\Sigma \beta_{i} c_{i}$ (see for instance Jørgensen, 1997; Jørgensen et al., 2000, where the considerations behind this equation are presented) for the Enteromorpha model as detritus $+4 \times$ entero $+150 \times$ 




Fig. 1. The conceptual model of the Enteromorpha dominated community.

crsmul. The weighting factor is used as an approximate value for mollusc and crustaceans (see the discussion in Marques et al., 1997). The eel grass model uses the following equation for the 


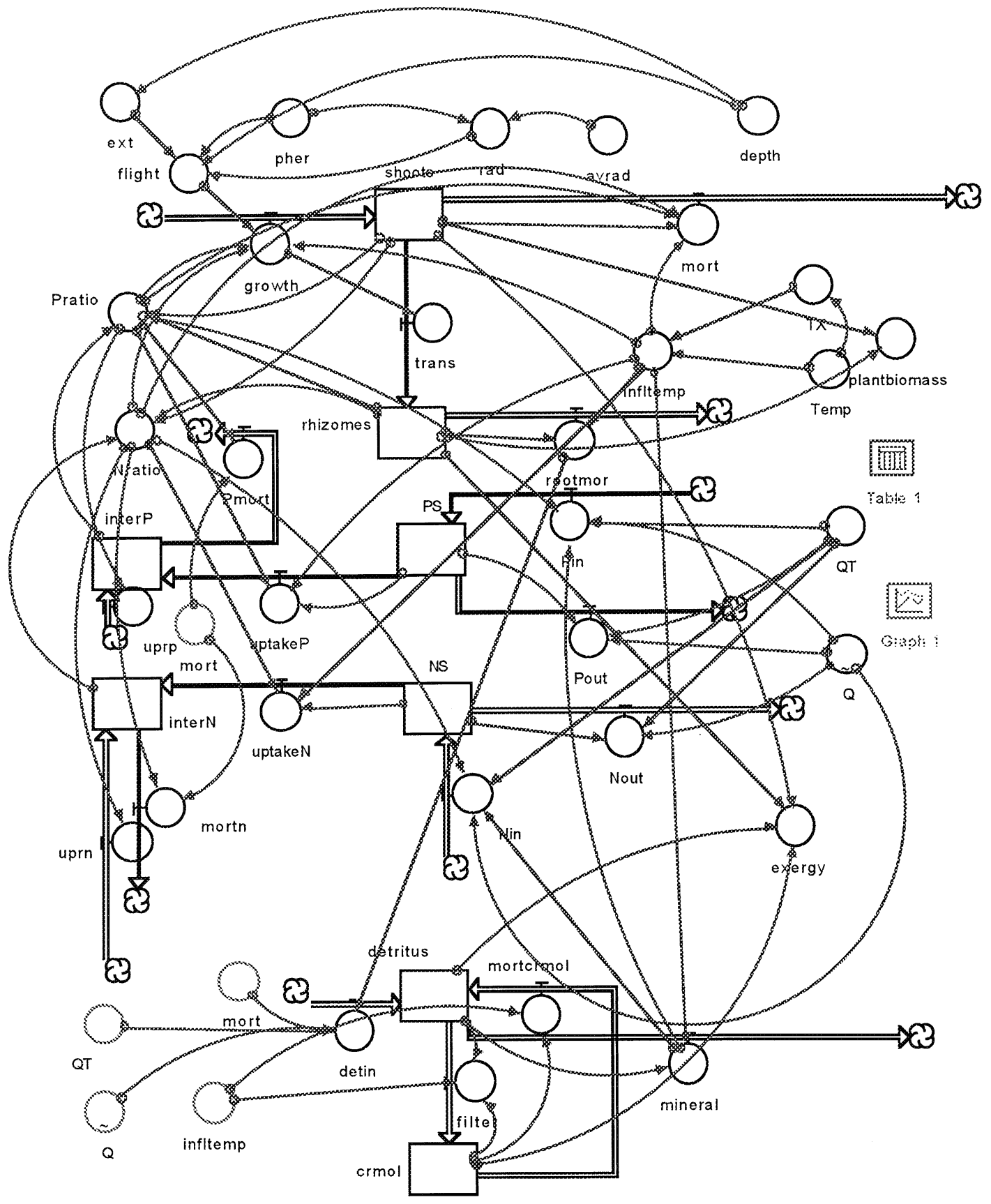

Fig. 2. The conceptual model of the Zostera dominated community.

computations of exergy: detritus $+20 \times$ (rhizomes + shoots $)+150 \times$ crmol. The weighting factor 20 is in accordance with the factor used by Coffaro et al. (1997). In this context, it must be 
emphasized that the exergy calculations have a high uncertainty due to our limited knowledge about the weighting factors, the $\beta$-values.

\section{The model results}

Figs. 3 and 4 show the results of the calibration which is based upon the freshwater discharge and the oxygen depletion (for Enteromorpha only) presented above. The peak exergy value is approximately the same namely about $11300 \mathrm{~g}$ detritus equivalent $/ \mathrm{m}^{2}$ at maximum for the two models.

Table 1 gives the exergy and plant biomass peak results of the following simulations:

A) The above mentioned calibration results with discharge of freshwater from day 213 to 365 with the peak at day 274. Phosphorus in the tide water is $670-700 \mu \mathrm{mol} / \mathrm{m}^{3}$ and in the freshwater $200 \mu \mathrm{mol} / \mathrm{m}^{3}$.

B) The above mentioned calibration results with discharge of freshwater from day 0 to 152 with the peak at day 63. Phosphorus in the tide water is $670-700 \mu \mathrm{mol} / \mathrm{m}^{3}$ and in the freshwater $200 \mu \mathrm{mol} / \mathrm{m}^{3}$.
C) The above mentioned calibration results with discharge of freshwater from day 0 to 152 with the peak at day. Phosphorus in the tide water is $670-700 \mu \mathrm{mol} / \mathrm{m}^{3}$ and in the freshwater 40 $\mu \mathrm{mol} / \mathrm{m}^{3}$.

D) The above mentioned calibration results with discharge of freshwater from day 0 to 365 with the peak at day 114. Totally, the annual discharge of freshwater is 3 times what it is in case A. Phosphorus in the tide water is $670-$ $700 \mu \mathrm{mol} / \mathrm{m}^{3}$ and in the freshwater $40 \mu \mathrm{mol} /$ $\mathrm{m}^{3}$.

E) The above mentioned calibration results with discharge of no freshwater. Phosphorus in the tide water is $670-700 \mu \mathrm{mol} / \mathrm{m}^{3}$.

\section{Discussion of the results}

Enteromorpha is growing faster than Zostera but is sensitive to too low salinity and is dependent on the presence of phosphorus and nitrogen in the water column. From an ecological management point of view the Zostera dominated community is preferred because the oxygen concentration is higher, the water is more clear and no crash due

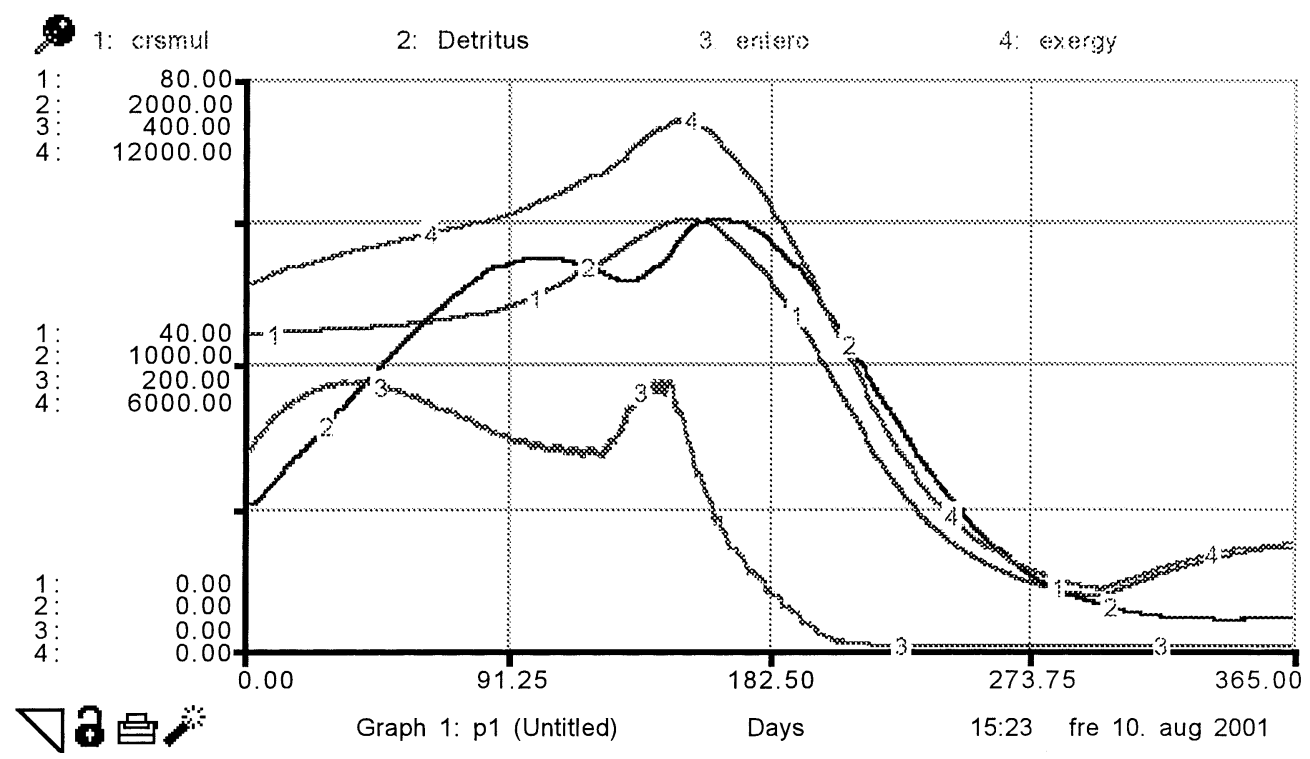

Fig. 3. The density $\left(\mathrm{g} / \mathrm{m}^{2}\right)$ of mollusca and crustacea, crsmul, detritus, Enteromorpha, entero and exergy (g detritus equivalents $\left./ \mathrm{m}^{2}\right)$ versus days. 


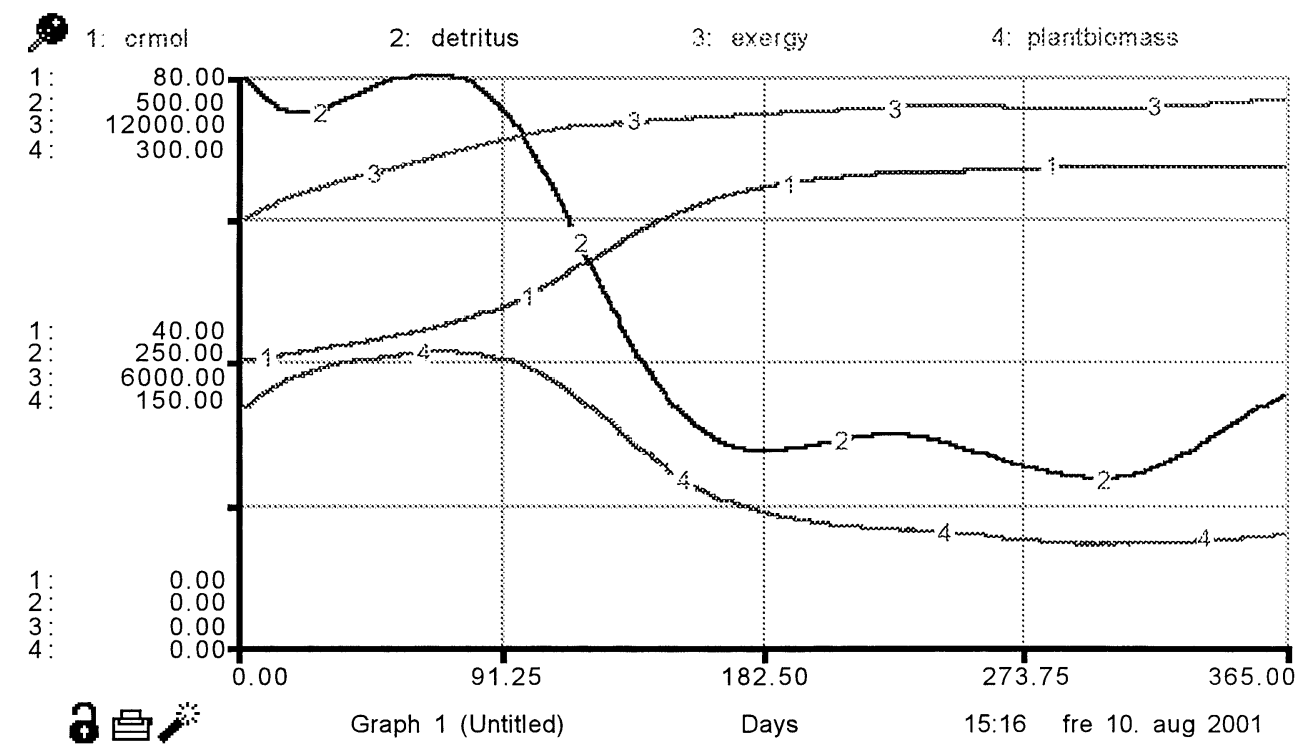

Fig. 4. The density $\left(\mathrm{g} / \mathrm{m}^{2}\right)$ of mollusca and crustacea, crmol, detritus, plant biomass (Zostera) and exergy (g detritus equivalents $\left./ \mathrm{m}^{2}\right)$ versus days.

to anaerobic conditions takes place. If the freshwater with high concentration of nutrients (particularly nitrogen) is discharged during the last part of the year, as it is often the case at present, Enteromorpha will be dominant, which is in accordance with Martins and Marques, in press. The exergy calculations show that the exergy is approximately the same for the two models by simulation A, which may be interpreted as the initial value may be crucial for the final results. Enteromorpha has the highest initial concentration according to observations (see for instance Marques et al., 1997) and the exergy is about the same. Therefore, the conditions corresponding to case A may lead to an Enteromorpha community. If we, however, shift the freshwater discharge to the beginning of the year, the exergy and the plant biomass of the Zostera community will hardly change (simulations B to D), while the exergy and biomass of the Enteromorpha will decrease significantly. The exergy and biomass of the Enteromorpha will decrease further if the phosphorus concentration in the freshwater is reduced, which could occur if a big amount of freshwater is discharged, since phosphorus is mainly produced in estuarine sediment (Martins and Marques, in press). A discharge of freshwater all year round does not change the exergy and biomass of the two

Table 1

\begin{tabular}{|c|c|c|c|c|c|c|}
\hline \multirow[t]{3}{*}{ Case } & \multirow{3}{*}{$\begin{array}{l}\text { Description: } \\
\mu \mathrm{mol} \mathrm{P} / 1\end{array}$} & \multicolumn{5}{|c|}{ Exergy and plant biomass peak values } \\
\hline & & \multirow[t]{2}{*}{ Discharge period } & \multicolumn{2}{|l|}{ Zostera } & \multicolumn{2}{|c|}{ Enteromorpha } \\
\hline & & & Exergy & Pl. Bio. & Exergy & Pl. Bio. \\
\hline A & 200 & $213-365$ & 11300 & 162 & 11300 & 318 \\
\hline B & 200 & $0-152$ & 11500 & 160 & 10500 & 248 \\
\hline $\mathrm{C}$ & 40 & $0-152$ & 11500 & 158 & 10300 & 233 \\
\hline $\mathrm{D}$ & 40 & $0-365$ & 11500 & 158 & 10300 & 235 \\
\hline $\mathrm{E}$ & No freshwater at all & & 11500 & 162 & 10200 & 318 \\
\hline
\end{tabular}


models compared with the cases B to D significantly. The Zostera model is independent on the salinity and is not very dependent on the phosphorus concentration in the water column.

The results should only be taken semi-quantitatively because the exergy calculations are very uncertain which also implies that the results are interpreted as exergy indices not as absolute exergy values. A semi-quantitative interpretation seems however to point toward some ecological management possibilities: artificial control of the freshwater discharges through the use of sluices, increasing the discharge during the first part of the year. Reduce the nutrient input from freshwater (and if possible also from tide water). By playing on these two possibilities it should be possible to reduce the probability for an Enteromorpha dominated community and give the Zostera dominated community better conditions. Lately, there has been an increased attention on the possibilities to modify the hydrology to achieve major improvements in aquatic ecosystems ( $\mathrm{Za}-$ lewski, 2000). It is called ecohydrology and is an ecological engineering subdiscipline. The results of this model study illustrate clearly the possibilities offered by ecohydrology.

\section{Conclusions}

The two models of two different possible structures in Mondego Estuary have been applied by calculation of the exergy to assess under which circumstances (freshwater discharge and nutrient concentrations) the two possible (Enteromorphas and Zostera) communities will prevail. As the exergy has approximately the same value for the two communities, when nutrient rich freshwater is discharged during the last part of the year, this should be avoided to ensure that the Zostera community becomes dominant. The Zostera community has the highest exergy when the freshwater is discharged in the first part of the year and when the freshwater has a low nutrient concentration. Consequently, the freshwater should be discharged early during the year and with as low a nutrient concentration as possible, to ensure dominance of the Zostera community.

The application of the maximum exergy principle to decide which community will be dominant under which conditions has great environmental management interest, as it often is important to be able to determine under which conditions a shift from one less desirable structure to a more desirable structure of an ecosystem will take place. This is generally the case when ecohydrology could be applied to obtain environmental improvements. More experience with other case studies is obviously needed, before any conclusion about the general applicability of the presented method can be made. Hopefully, it will be possible in a few years to have gained experience with a sufficient number of case studies to be able to decide on the general applicability of the here applied method.

\section{References}

Bocci, M., Coffaro, G., Bendoricchio, G., 1997. Modelling biomass and nutrient dynamics in eel grass: application to the Lagoon of Venice (Italy) and Øresund (Denmark). Ecol. Model. 102, 67-80.

Coffaro, G., Bocci, M., Bendoricchio, G., 1997. Application of structural dynamic approach to estimate space variability of primary producers in shallow marine water. Ecol. Model. 102, 97-114.

Duarte, P., 1995. A mechanistic model of the effects of light and temperature on algal primary productivity. Ecol. Model. 82, $151-160$.

Jørgensen, S.E., 1992. Development of models able to account for changes in species composition. Ecol. Model. 62, 195208.

Jørgensen, S.E., 1997. Integration of Ecosystem Theories: a pattern, second ed. (first edition 1992). Kluwer Academic Publishers, Dordrecht, Boston, London, p. 400.

Jørgensen, S.E., Patten, B.C., Straskraba, M., 2000. Ecosystem emerging IV: growth. Ecol. Model. 126, 249-284.

Jørgensen, S.E., Bendoricchio, G., 2001. Fundamentals of Ecological Modelling, third ed.. Elsevier, Oxford.

Jørgensen, S.E., Ray, S., Berec, L., Straskraba, M., Improved Calibration of a Eutrophication Models by Use of the Size Variation due to Succession. Submitted to Ecological Modelling, submitted for publication.

Marques, J.C., Pardal, M.A., Nielsen, S.N., Jørgensen, S.E., 1997. Analysis of the properties of exergy and biodiversity along an estuarine gradient of eutrophication. Ecol. Model. $102,155-168$. 
Martins, I., Marques, J.C., A model for the growth of opportunistic macroalgae (Enteromorpha sp.) in tidal estuaries. In: Estuarine Coastal and Shelf Science, in press.
Zalewski, M., 2000. Ecohydrology, the scientific background to use ecosystem properties as management tool toward sustainability of freshwater resources. Ecol. Eng. 16, 1-8. 